\section{A logical development: biomedicine's fingerprints are on the instrument of close reading in Charonian Narrative Medicine}

\author{
Shane Neilson
}

\begin{abstract}
Narrative Medicine as originated by Rita Charon began as an attempt to redress the unopposed biomedicalisation of the medical profession. Although the movement has been self-positioned as a corrective to deliver an ideal of care, it began within the rhetorical framework of biomedicine and not outside of it. Thus, Narrative Medicine justifies itself in biomedical terms, invoking instrumental rationales for its use. This seeming 'scientification' of narrative is only half of the biomedicine-indebted Narrative Medicine story. An equally important but asyet unmentioned debt is the quasi-scientific origin story of Narrative Medicine's signature method of close reading. Thus, there is an inherent paradox at the heart of the Narrative Medicine movement: designed to resist a reductive biomedicine, it exists in a dependent relationship on biomedicine at the level of justification and at the level of praxis. Thus, it is an open question if the Narrative Medicine movement is the proper vehicle for a rebalancing of humanities and biomedicine.

\section{THE EPISTEMOLOGICAL SIMILITUDE OF BIOMEDICINE AND CHARONIAN NARRATIVE MEDICINE}

As designed and propagated by Rita Charon and her colleagues at Columbia University, ${ }^{1}$ Narrative Medicine (hereafter referred to as Charonian Narrative Medicine (CNM)) began as a project intended to check a widely acknowledged problem, the biomedicalisation of clinical practice via the introduction of methods from the humanities. 'Narrative Medicine: A Model for Empathy, Reflection, Profession, and Trust' deploys a rhetoric of lack concerning biomedicine's largely unopposed stewardship of then-contemporary medical practice:

Despite medicine's recent dazzling technological progress in diagnosing and treating

Department of English, University of Ottawa, Ottawa, Ontario, Canada

Correspondence to Dr Shane Neilson, Department of English, University of Ottawa, Ottawa, ON K1N 6N5, Canada; neilss@mcmaster.ca illnesses, physicians sometimes lack the capacities to recognize the plights of their patients, to extend empathy toward those who suffer, and to join honestly and courageously with patients in their illnesses. A scientifically competent medicine alone cannot help a patient grapple with the loss of health or find meaning in suffering. (Charon 2001, 1897)

The same rhetoric of lack is deployed again in 2016 when valorising Narrative Medicine's brand of close listening: 'That such listening was perhaps better achieved in the time of Hippocrates and Galen and Chekhov than in contemporary practice alerts us to deep-seated tensions within a contemporary bioscientific ethos that challenges the particular with the universal, the personal with the corporate, and the intimate with the mechanized' (Charon et al. 2016, 157-8). Thus, CNM was created in response to biomedicine's lack in many domains of care, and Charon's means of remediation largely occurs within a rhetorical frame of complementarity. In the JAMA article, Charon preserves the core utility of a 'scientifically competent medicine' to help 'a patient grapple with the loss of health' (Charon 2001, 1897) but (uncontroversially) points out that science is not enough for a good doctor. Her essay gently 'describes narrative competence' and 'suggests that it enables the physician to practice medicine with empathy, reflection, professionalism, and trustworthiness (ibid). Yet this humbler tone often switches to a rhetoric more akin to transformation. For example, at the level of a single sentence, consider 'As a model for medical practice, narrative medicine proposes an ideal of care and provides the conceptual and practical means to strive toward that ideal' (ibid). Now we are in the presence of idealisation in contradistinction to the aforementioned 'scientifically competent medicine alone'. Charon's rhetoric in the abstract is sweeping:

With narrative competence, physicians can reach and join their patients in illness, recognize their own personal journeys through medicine, acknowledge kinship with and duties toward other health care professionals, and inaugurate consequential discourse with the public about health care. By bridging the divides that separate physicians from patients, themselves, colleagues, and society, narrative medicine offers fresh opportunities for respectful, empathic, and nourishing medical care. (ibid)

In many sections of the article, Charon displays an ambivalence between offering Narrative Medicine to adjust medical practice in a measured, collegial way versus offering it to singlehandedly fix all the dilemmas facing contemporary medical practice due to its 'scientifically competent medicine alone' preference. ${ }^{2}$ This ambivalence becomes less pronounced as time goes on, lost in favour of loftier rhetoric. For example, Charon pushes transformative rhetoric further in Narrative Medicine: Honouring the Stories of Illness when she writes,

I have been humbled and impressed of late to meet with large and diverse groups of health care professionals and patients in this country and abroad who are fired up with yearnings for a medicine that makes sense, that takes care of people-both patients and caregivers-and that replenishes and respects all who are marked by it. To offer narrative medicine as a corrective to some of these failings, a support to these emerging strengths, and response to these widespread yearnings serves to unify and cohere divergent aspects of sickness and health care. (Charon 2006, ix)

Narrative Medicine is now a corrective, rather than a complementary force. To move to the most recent state-of-themovement compendium, The Principles and Practice of Narrative Medicine,

Narrative medicine began as a rigorous intellectual and clinical discipline to fortify healthcare with the capacity to skillfully receive the accounts persons give of themselves-to recognize, absorb, interpret, and be moved to action by the stories of others. It emerged to challenge a reductionist, fragmented medicine that holds little regard for the singular aspects of a patient's life and to protest the social injustice of a global healthcare system that countenances tremendous health disparities and discriminatory policies and practices. (Charon et al. (2016))

What was once unthreateningly deemed '[n]ot so much a new specialty as a new frame for clinical work' (1898) has, retroactively, become a 'rigorous intellectual and clinical discipline to fortify healthcare' whose stated enemy is a 'reductionist' medicine that 'holds little regard for the singular aspects of a patient's life'-meaning, biomedicine. 
Lock and Nguyen 2010, 11) write in An Anthropology of Biomedicine, concerns 'a systematic and ultimately scientific approach to knowledge about the body and its management ... grounded by knowledge produced by decontextualizing the body and subjecting it to an anatomical gaze'. The authors update this epistemological formulation in a new edition of their text, writing that biomedicine is 'a sociotechnical system' that is based 'on biological sciences', the latter providing 'a set of standards, protocols, and algorithms that enable the production of knowledge and practices to treat ailing individuals ... Biomedicine, in theory then, is based on an assumption on the universality of human bodies that everywhere are biologically equivalent' (Lock and Nguyen 2018, $1)$.

The bona fides of CNM operating from within the tent of biomedicine are numerous. In CNM, narrative is deployed in an instrumental fashion that is completely consistent with biomedical practice. For example, Charon writes: '[P] hysicians need ... narrative competence, that is, the competence that human beings use to absorb, interpret, and respond to stories' (Charon 2001, 1897). By invoking 'competence', CNM inaugurates a skillsbased, applied frame for the movement. To substantiate the instrumentalist point further, Charon writes of the consequences of not practising with narrative competence using a biomedically inflected rhetoric of outcomes:

If the physician cannot perform these narrative tasks, the patient might not tell the whole story, might not ask the most frightening questions, and might not feel heard. ${ }^{50}$ The resultant diagnostic workup might be unfocused and therefore more expensive than need be, the correct diagnosis might be missed, the clinical care might be marked by noncompliance and the search for another opinion, and the therapeutic relationship might be shallow and ineffective. (Charon 2001, 1899)

The whole point of Narrative Medicine, then, is to practice biomedicine better by using honed clinical skills that borrow from the humanities according to a programme that is overtly scientific in presentation. In the JAMA article, Charon writes that Narrative Medicine's 'hypotheses to be tested are provocative and wide ranging' (Charon 2001, 1900). Furthermore, she writes that in addition to 'outcomes research' are 'scholarly efforts to uncover the basic mechanisms, pathways, intermediaries, and consequences of narrative practices, supplying the "basic science" of theoretical foundations and conceptual frameworks for these new undertakings' (Charon 2001, 1901). We are again in a biomedicine-plus formulation of complementarity. CNM and biomedicine became epistemologically indistinguishable as CNM explicitly valorised its scientifically validated substantiation, seeking equality in the evidence-based medicine paradigm. Charon is on record in 2017 as boldly claiming that "[w]e have shown at Columbia that rigorous close reading can be taught and learned in clinical settings, where its dividends have been found to enhance patient care" (Charon, DasGupta, and Hermann 2016, 165). ${ }^{3}$ This is a scientific methodizing of the Narrative Medicine methodology. Indeed, the metaphors used in The Principles and Practice of Narrative Medicine suggest there is an outright aspiration to biomedical practice: 'close reading fortified with attention to its subjective dimensions has become narrative medicine's laboratory and training ground' (Charon, DasGupta, and Hermann (2016), 158).

Perhaps this article strikes the reader as an attack akin to Strawson's polemic against the hegemonic imposition of narrative hermeneutics to subjectivity (Strawson 2004). I hasten to reassure readers of that, although I have serious concerns about the transformational power of CNM, I am a believer in the necessity of the redress of biomedicine and that I support the introduction of texts broadly defined and attendant close reading as pedagogical techniques. To be fair, Charon had to start somewhere, and it is understandable that Narrative Medicine was constructed as a field operating from within biomedicine, designed to access biomedical halls. For a method of change to take hold, a certain degree of familiarity is a good strategy. Furthermore, Charon operated among historical conditions that perceived literature as having less utility than other domains in the humanities, such as history and ethics. Ann Hudson Jones writes, 'It is not surprising that, more often than not, [scholars who offered literature as germane to medical education] emphasised practical utility-what literature can do for medical education and practice' (Jones 2013, 416). Charon makes a logical evolution when she states that operating within the medical humanities themselves was 'restrictive' (Charon 2012) because literature itself was seen as a frill that could be ignored at will by medical faculties, whereas the clinical centring inherent to Narrative Medicine at the branding level made it a much better candidate for funding support. To make the study of literature more palatable to medicine, it had to look more like medicine. There is nothing deceptive about this, for Charon is on record as being relatively uninterested in the humanities. Jones (2013) writes, 'Her first definitions of the term [Narrative Medicine] make very clear that Narrative Medicine is a medical practice of physicians. As a physician herself, Charon is understandably interested most of all in the practice of medicine'. Quoting Charon herself, Jones adds that Charon is 'not so much committed to literary studies or even to the humanities' (Jones 2013, 426-7).

The question must be asked: Can one usher in transformative change if one's proposed transformation operates according to the same principles as one's stated target of change? Is Charon's aforementioned goal of 'fortification' possible when the 'rigorous intellectual and clinical discipline' called Narrative Medicine operates from within the epistemology of biomedicine itself? Can Narrative Medicine, an applied-humanities programme operationalised in a biomedical context, result in the aforementioned 'correction' or an 'ideal of care'?

Many would claim 'no'. The critique of the instrumentality of health humanities pedagogy, of which CNM has been a dominant player, has been sounding strongly for some time now. Alan Bleakley recently pointed out that 'the art of medicine ... has been frustrated by medical education's commitment to functional approaches embodied particularly in learning professional communication through simulation, and in reducing complex clinical learning to menus of instrumental competencies' (Bleakley 2020,). Victoria Tischler is even more explicit, writing that 'the input of creatives and the arts that they offer are often instrumentalized, that is, considered a type of treatment much like a dose of medication' (Tischler 2020, 85). Such discourse is often framed in biomedical terms incorporating intervention, evidence and standardised measurement, effectively reflecting the ongoing dominance of biomedicine in Western health care (ibid).

With my own re-framing of Charon's 'new frame for medical practice' as, in actuality, a replacement of the old biomedical frame, I now turn to an unacknowledged paradox inherent to Narrative Medicine's 'signature technique' of close reading.

\section{CLOSE READING: A 'SIGNATURE METHOD' WITH ITS OWN ORIGIN STORY IN SCIENCE}

Charon's potted history of close reading in The Principles and Practice of Narrative Medicine places the technique's origin with IA Richards in the early 1920s, and 
then fills out the history of the technique by running it through the decades, sketching a bit more New Criticism, then structuralism, the deconstructive turn, New Historicism, Lacanian psychoanalysis, postmodernism and queer theory. The revealing thing about the history is not what it tells, but what it does not notice about what it tells. For example, Charon writes of Richards that he emphasised 'attention to individual readers' interpretive process in addition to the attention to the text itself' (Charon, DasGupta, and Hermann 2016, 159). In this regard, Richards is both founding member of New Criticism and the reader response method to come, but what is crucially important to recognise (and what Charon elides) is that Richards, like Empson and many other practitioners of New Criticism, was essentially a linguist at heart. The available archive with which to capture Richards in search for a mechanistic model for hermeneutics is vast. ${ }^{4}$ Consider also the moment when Charon describes New Criticism as valorising

extremely focused readings, mostly of poems, with no attention to the contexts of the poems or to objective correlatives in the life experience of the poet. In an effort to systematize the reading of poetry toward a scientific analysis, the New Critics proposed that seeking the author's intention in writing or the reader's emotional response to a text-what they called the intentional falla$c y$ and the affective fallacy - could misdirect the critic's effort to understand the poem. (Charon, DasGupta, and Hermann (2016), 160)

In both instances, we have a literary technique with aspirations to science, a kind of reading that is uncannily biomedical in practice. At a key point in the original JAMA article, Charon distinguishes between 'logicoscientific knowledge' - where a 'detached and replaceable observer generates or comprehends replicable and generalisable notices'-and 'narrative knowledge'-where 'local and particular understandings about one situation by one participant or observer' are obtained (Charon 2001, 1898). Yet the origins of the close reading method are exactly as Charon states: spurred by the desire to scientificize hermeneutics. Just like Charon's 'logicoscientific knowledge', close reading's origin is one that tries to remove context in order to get at objective truth. Yet close reading is valorised by Charon as a way to glean 'narrative knowledge', meaning the illumination of 'the universally true by revealing the particular', whereas '[l]ogicoscientific knowledge attempts to illuminate the universally true by transcending the particular' (Charon 2001, 1898). The paradox is never fully recognised by Charon. Perhaps to see this paradox would require looking at biomedicine from the outside?

Working from within biomedicine inevitably leads to the formation of other blind spots. When moving to the present-day discussion of the reductionist tendencies of biomedicine vis-à-vis neuroimaging to map 'profound human experiences', Charon fondly recalls reader response studies, a mode of criticism fashionable in the 1980s that 'sought to understand the interior activities of the reader' (Charon, DasGupta, and Hermann (2016), 163). When Charon compares it favourably to New Criticism's 'objective and analytic goals towards an interest in the subjectivity of reading and a commitment to explore and understand it' (Charon, DasGupta, and Hermann 2016, 164)-indeed, Richards pioneered the technique-one wonders just what magnitude of confusion is occurring, for reader response therapy did reflect a shift in emphasis from a seeming objectivity to a seeming subjectivity, yet the backdrop for the shift remains the realm of quasi-scientific fantasy, for a significant tendency within reader response theory (admittedly, a very heterogenous group of practitioners) was the use of psychological experimentation on defined sets of readers. For example, in Style and Reader Response, the authors describe the multitude of methods available:

The experiment may take place in quasilaboratory conditions and involve reading very small chunks of a narrative, perhaps using think-aloud data, structured interviews, and/or the collection of written responses from readers $\ldots$ or readers completing a questionnaire... [e]xperimental approaches tend to test hypotheses and generate data that is analyzed quantitatively, although qualitative analysis can form part of interpreting the data'. (Bell et al. 2021, 10)

By mentioning functional MRI and comparing it unfavourably to reader response theory, Charon unwittingly casts shade on the most recent magic lantern by bringing forward a more antique one.

Although Charon's history moves to a new valorised method, CNM's brand of close reading, which 'has sequentially been informed, fortified, challenged, and sharpened by intellectual and creative cultural movements' (Charon, DasGupta, and Hermann 2016, 162), the fact that her signature technique has returned to its origin point is entirely missed. Any kind of close reading that can be systematically taught and then assessed in scientific studies to be proven as effective in clinical settings is a biomedical technique by virtue of setting and method. We should now recognise that Narrative Medicine's current practice has a very old historical basis that is part of a larger story involving the rise of the natural sciences as our dominant paradigms for authoring our subjectivities. My point is not that Narrative Medicine is unaware that it is biomedical; my point is that its one claim to humanistic practice, the close reading technique, has its origins in logical positivism. In other words, Narrative Medicine is unaware of just how biomedical it is.

It is probably time to finally correct Charon's identification of the origin point of her 'signature technique' to the philosophical milieu in which it was generated around the turn of the 1920s, slightly before Charon's identification with the New Critics.

It was the non-Western Russian Formalists in the late 1910s who were first invested in transforming the study of literature into a science. For example, Roman Jakobson, who got his start in the Moscow Linguistic Circle, one of the two leading groups of Russian Formalists, referred to the 'object of literary science' as 'not literature but literariness, that is, what makes a given work a literary work' (Steiner 1984, 23). Eichenbaum, a member of the St. Petersburg-based Society for the Study of Poetic Language and a colleague of Viktor Shklovsky's (Shklovsky being the most famous of the group), wrote:

the Formal method, by gradually evolving and extending its field of inquiry, has completely exceeded what was traditionally called methodology and is turning into a special science that treats literature as a specific series of facts... What characterizes us is neither 'Formalism' as an aesthetic theory, nor 'methodology' as a closed scientific system, but only the striving to establish, on the basis of specific properties of the literary material, an independent literary science. (Steiner 1984, 22)

The Russian Formalists reduce language to constituent parts so that the enterprise can be seen as a science:

'what is significant about the Formal method?' Shklovsky wrote in his characteristic staccato style: 'What is significant is that we approached art as production. Spoke of it alone. Viewed it not as a reflection. Found the specific features of the genus. Began to establish the basic tendencies of form. Grasped that on a large scale there is a real 
homogeneity in the laws informing works. Hence, the science [of literature] is possible. (Steiner 1984, 65)

The parallel between biomedicine and Russian Formalism is obvious. Biomedicine's project is a systematic one that seeks to render the body as data. For its part, Narrative Medicine, too, teaches a technique designed to obtain data that has practical use.

To be fair to CNM, Russian Formalism is as much of an intellectual ancestor to $\mathrm{CNM}$ as any other subsequent manifestation of literary theory. The Russian Formalist project underwrites all current literary scholarship, no matter the tradition; the Formalist way of reading has proven a powerful hermeneutic. Yet it, too, is part of the same cultural conditions created by the philosophy of positivism which, as Steiner-the definitive historian of the Russian Formalists-suggests as an influence circulating as far back as the 1870s (Steiner 1984, 64). Evidencebased medicine, for example, is but one member of a host of offshoot traditions. In a notable paper critiquing evidence-based medicine, Maya Goldenberg identifies the 'Vienna School' of philosophers and scientists from the 1920s who 'rejected the possibility of justifying knowledge claims that were "beyond" the scope of science, they dismissed metaphysics and many of the claims made in theology and ethics as nonsensical (or unverifiable)' (Goldenberg 2006, 2622). Logical positivism and Russian Formalism are intellectual fellow travellers. For the logical positivists, science provided a 'value-free understanding of the natural world' (ibid) and the same was so for the Russian Formalists when it came to literature, as it was for the New Critics. The impact of the Vienna School and the larger cultural ferment that spawned it makes developments like a disparate group of literary scholars attempting to science-ify their discipline a logical development.

Yet delivery on the promises of CNMthe aforementioned 'bridging divides', etc-has not resulted in a meaningful check on biomedicine despite CNM's impressive international success. One has to wonder if any triumphally instrumentalist programme-in other words, anything that fundamentally misunderstands the transformative power of art-could make such a difference in a discipline so wholly invested in biomedicine. The biomedical integration of CNM is complete, from method to context to demonstrated proof of efficacy. The unintended result is a fortification of biomedicine, not a correction or rebalancing of medical practice.

\section{Twitter Shane Neilson @sneilsonwwh}

Contributors SN wrote this article of his own accord. He did the research and generated the text. As guarantor, he accepts full responsibility for the work and controlled the decision to publish.

Funding This research was supported by a SSHRC Postdoctoral Grant.

Competing interests None declared.

Patient consent for publication Not applicable.

Ethics approval This study does not involve human participants.

Provenance and peer review Not commissioned; externally peer reviewed.

Data availability statement There are no data in this work.

\section{(2) OPEN ACCESS}

Open access This is an open access article distributed in accordance with the Creative Commons Attribution Non Commercial (CC BY-NC 4.0) license, which permits others to distribute, remix, adapt, build upon this work non-commercially, and license their derivative works on different terms, provided the original work is properly cited, appropriate credit is given, any changes made indicated, and the use is non-commercial. See: http:// creativecommons.org/licenses/by-nc/4.0/.

(c) Author(s) (or their employer(s)) 2022. Re-use permitted under CC BY-NC. No commercial re-use. See rights and permissions. Published by BMJ.

\section{(D) Check for updates}

To cite Neilson S. Med Humanit Epub ahead of print: [please include Day Month Year]. doi:10.1136/ medhum-2021-012301

Accepted 4 January 2022

Med Humanit 2022;0:1-4. doi:10.1136/

medhum-2021-012301

\section{ORCID iD}

Shane Neilson http://orcid.org/0000-0002-5732-5338

\section{NOTES}

1. The history of narrative concerns in medicine predates Charon significantly. This article is squarely focused on the dominant North American application of narrative in medical education.

2. Narrative Medicine's programme is suggested as solution amid a set of potentiated imperatives amid a medical domain lacking empathy. For example, 'Only when physicians have the narrative skills to recognise medicine's ideals, swear to one another to be governed by them, and hold one another accountable to them can they live up to the profession to serve as physicians'. One could split the hair that Charon's not saying that her programme would deliver upon this promise, but again, that conclusion is implicit, and it is a conclusion that is made explicit in later writings. There are other similar 'only' constructions in the article.

3. The evidence cited is a paper in Academic Medicine (Charon, Hermann, and Devlin 2016).

4. A critique of the popular "New Criticism is "scientism" of the arts' bandwagon was taken up in the 1970s by figures like Graff (1974). Albeit unconvincing in his defence of the New Critics, even Graff writes that the case of Richards as literary scientist is accurate.

\section{BIBLIOGRAPHY}

Bell, A., S. Browse, A. Gibbons, and D. Peplow. 2021. "Responding to Style." In Style and Reader Response: Minds, Media Methods, edited by Alice Bell, Sam Browse, Alison Gibbons, and David Peplow. Amsterdam: John Benjamins B.V.

Bleakley, A. 2020. "Introduction: The Medical Humanities: A Mixed Weather Front on a Global Scale." In Routledge Handbook of the Medical Humanities. London: Routledge.

Charon, R. 2001. "Narrative Medicine: A Model for Empathy, Reflection, Profession, and Trust." JAMA 286 (15): 1897-1902. https://doi.org/

Charon, R. 2006. Narrative Medicine: Honouring the Stories of Illness. Oxford: Oxford UP.

Charon, R. 2012. "Deep Structures, or How Our Work Improves the Care of the Sick. " Plenary Presentation at the PRIME 2012 National Conference: Project to Rebalance and Integrate Medical Education. Louisville. ITunes $U$.

Charon, R., D. Sayantani, H. Nellie, and I. Craig. 2016. The Principles and Practice of Narrative Medicine. Oxford: Oxford University Press.

Charon, R., N. Hermann, and M. J. Devlin. 2016. "Close Reading and Creative Writing in Clinical Education: Teaching Attention, Representation, and Affiliation." Academic Medicine 91 (3): 345-50.

Charon, R., S. DasGupta, N. Hermann, et al. 2016. The Principles and Practice of Narrative Medicine. Oxford: Oxford University Press.

Goldenberg, M. J. 2006. "On Evidence and Evidence-Based Medicine: Lessons from the Philosophy of Science." Social Science \& Medicine 62 (11): 2621-32.

Graff, G. 1974. "What Was New Criticism? Literary Interpretation and Scientific Objectivity." Salamagundi 27: 72-93.

Jones, A. H. 2013. "Why Teach Literature and Medicine? Answers from Three Decades." The Journal of Medical Humanities 34 (4): 415-28.

Lock, M. M., and V.-K. Nguyen. 2010. An Anthropology of Biomedicine. Hoboken, NH: Wiley-Blackwell.

Lock, M. M., and V.-K. Nguyen. 2018. An Anthropology of Biomedicine. 2nd ed. Hoboken, NH: Wiley-Blackwell.

Steiner, P. 1984. "Russian Formalism: A Metapoetics." Poetics Today 5 (4): 889.

Strawson, G. 2004. "Against Narrativity." Ratio 17 (4): 428-52.

Tischler, C. 2020. "Health Humanities and the Creative Disciplines." In Routledge Companion to the Health Humanities, edited by Paul Crawford, Brian Brown, and Andrea Charise, 85-90. London: Routledge. 